\title{
Uso de Medicações por Via Subaracnóidea no Tratamento da Dor Crônica*
}

\author{
Intrathecal Drugs for Chronic Pain Control
}

Anita Perpétua Carvalho Rocha ${ }^{1}$, Lino Lemonica TSA ${ }^{2}$, Guilherme Antônio Moreira de Barros ${ }^{3}$

\begin{abstract}
RESUMO
Rocha APC, Lemonica L, Barros GAM - Uso de Medicações por Via Subaracnóidea no Tratamento da Dor Crônica

Justificativa e Objetivos - A dor crônica é um desafio para a Medicina atual. Novos métodos e medicamentos têm sido propostos com o intuito de controlar os sintomas álgicos. A via de administração subaracnóidea tem se mostrado como uma alternativa viável e segura, embora necessite continuamente ser objeto de estudo de muitos pesquisadores. O objetivo deste trabalho é fazer uma revisão dos medicamentos disponíveis no arsenal terapêutico já consagrados pelo uso e os que se mostram promissores na atualidade para a prática clínica diária.

Conteúdo - Nesta revisão são avaliados vários fármacos que apresentam ação analgésica quando utilizada via neuroeixo. Opióides, anestésicos locais, agonistas $\alpha_{2}$-adrenérgicos, antagonistas dos aminoácidos excitatórios e inibitórios, acetilcolina, inibidores da acetilcolinesterase, bloqueadores dos canais de cálcio, adenosina, serotonina, antidepressivos tricíclicos e inibidores da síntese de prostaglandinas são analisados no que concerne aos seus efeitos farmacológicos, incluindo os indesejáveis.
\end{abstract}

Conclusões - Muitos avanços foram registrados no controle dos sintomas álgicos após a utilização das substâncias citadas por via raquidiana, onde certamente algumas serão aproveitadas e enriquecerão o arsenal terapêutico e outras relegadas temporária ou definitivamente. Entretanto, ainda serão necessários muitos estudos clínicos e experimentais para que estes conhecimentos possam ser incorporados e utilizados com segurança pelos profissionais que lidam com o tratamento da dor crônica.

UNITERMOS - DOR, Crônica; TÉCNICAS ANESTÉSICAS, Regional: subaracnóidea

\section{INTRODUÇÃO}

dor é uma qualidade sensorial complexa, freqüentemente não relacionada ao grau de lesão tecidual. Segundo a Associação Internacional para o Estudo da Dor

\footnotetext{
* Recebido do (Received from) Serviço de Terapia Antálgica e Cuidados Paliativos do Departamento de Anestesiologia da Faculdade de Medicina de Botucatu (FMB - UNESP), Botucatu, SP

1. $\mathrm{ME}_{3}$ do CET/SBA do Departamento de Anestesiologia, Serviço de Terapia Antálgica e Cuidados Paliativos, da FMB - UNESP

2. Professor Assistente Doutor do CET/SBA do Departamento de Anestesiologia da FMB - UNESP; Responsável pelo Serviço de Terapia Antálgica e Cuidados Paliativos

3. Anestesiologista do CET/SBA da FMB - UNESP

Apresentado (Submitted) em 26 de outubro de 2001

Aceito (Accepted) para publicação em 25 de janeiro de 2002

Correspondência para (Mail to)

Dr. Lino Lemônica

Dept ${ }^{\circ}$ de Anestesiologia da FMB - UNESP

Distrito de Rubião Junior

18618-970 Botucatu, SP

E-mail: linol@fmb.unesp.br

(C) Sociedade Brasileira de Anestesiologia, 2002
}

\author{
SUMMARY \\ Rocha APC, Lemonica L, Barros GAM - Intrathecal Drugs for \\ Chronic Pain Control
}

Backgroud and Objectives - Chronic pain is a challenge for modern medicine. New methods and drugs have been proposed to control pain. Intrathecal administration is a feasible and safe option, but still requires further investigations. This study aimed at reviewing available and well established drugs as well as new promising alternatives for the daily practice.

Contents - Several neuraxial drugs with analgesic action are reviewed. Desirable and undesirable effects of opioids, local anesthetics, $\alpha_{2}$-agonists, excitatory and inhibitory aminoacid antagonists, acetylcholine, acetyl-cholinesterase inhibitors, calcium channel blockers, adenosine, serotonin, tricyclic antidepressants and prostaglandin synthesis inhibitors are analyzed. Conclusions - Several advances were achieved in controlling pain with intrathecal administration of the above-mentioned drugs. Certainly some will be used, thus enriching therapeutic armamentarium, and others will be temporarily or permanently abandoned. However, several clinical and experimental studies will still be needed for knew knowledge to be incorporated and safely used by professionals dealing with chronic pain.

KEY WORDS - ANESTHETIC TECHNIQUES, Regional: spinal block; PAIN, Chronic
(AIED), é definida como uma sensação e experiência emocional desagradável associada a um dano tissular real ou potencial.

Dor é um sintoma freqüente na prática clínica e afeta o ser humano de forma aguda e crônica. Ador aguda tem um papel fisiológico importante, apresentando-se como um sinal de alerta diante de possíveis ameaças. Já a dor crônica não tem um papel biológico definido e pode ser considerada como a que persiste além do tempo razoável após a cura da lesão que a originou. Em geral, é tida como patológica, estando associada à incapacidade e ao estresse físico, econômico e emocional. É uma queixa comum em pacientes portadores de diferentes doenças e seu tratamento é um desafio para os profissionais de saúde, que buscam incessantemente novas estratégias terapêuticas.

Analgésicos sistêmicos e terapias conservadoras são efetivas no controle da dor da maioria dos pacientes. Entretanto, em muitos casos, principalmente nos portadores de dor neuropática, são necessários tratamentos mais agressivos. Métodos reversíveis que modulam a transmissão da dor em nível espinhal são propostos e incluem a estimulação elétrica 
medular e a injeção subaracnóidea de analgésicos, seja por bolus de demanda ou através da implantação de bomba de infusão contínua ou equipamentos de infusão controlados pelo paciente.

No presente, a morfina é a única droga aprovada pela United States Food and Drug Administration (FDA) para uso contínuo no espaço subaracnóideo. Entretanto, estudos clínicos e em animais têm sido realizados no intuito de propor novas alternativas para o uso de opióides. Estes estão associados a efeitos colaterais indesejáveis e a um estigma fortíssimo entre leigos ou mesmo entre médicos, fatos que têm contribuído para a busca de novos medicamentos analgésicos adjuvantes. Desta forma, tem sido proposto o uso raquidiano de outras classes de fármacos para o manuseio da dor.

Muitos receptores e substâncias que modulam a transmissão da dor têm sido identificados. Existe enorme variedade de agentes que atuam especificamente ou não em receptores e é provável que a sua utilização, isolada ou combinada, implique em maior controle dos sintomas álgicos com menor ocorrência de efeitos indesejáveis.

A aplicação de substâncias no espaço raquidiano é, via de regra, realizada através de bomba de infusão. Entretanto, a utilização desta forma de administração está associada a possíveis e eventuais complicações. Acredita-se na necessidade da criação de mecanismos alternativos para a administração de analgésicos no estojo raquidiano, o que tem motivado a realização de numerosos estudos experimentais laboratoriais e clínicos. Antevê-se que em futuro próximo a implantação de células e de substâncias encapsuladas nesse espaço poderá ser utilizada para o alívio da dor crônica ${ }^{1}$.

\section{ANALGÉSICOS ESPINHAIS}

Opióides (morfina, fentanil e sufentanil)

Os opióides são medicações comumente utilizadas na prática clínica para o tratamento da dor em pacientes portadores de doenças agudas e crônicas. O seu emprego é observado em diversas situações e por diferentes vias de administração: oral, parenteral ou espinhal. O que irá determinar a via preferencial é o quadro clínico do doente e as características farmacocinéticas dos medicamentos utilizados.

A multiplicidade das ações exercidas pelos opióides é resultado da interação dos mesmos com diferentes tipos de receptores. Estudos evidenciam a existência de vários receptores, sendo os mais aceitos os MU $(\mu)$, KAPPA (K), SIGMA

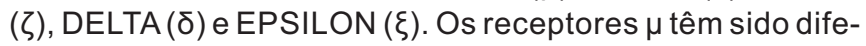
renciados em dois subtipos: $\mu 1$, de alta afinidade para opióides e $\circ \mu 2$, de baixa afinidade.

As atividades dos medicamentos opióides manifestam-se de acordo com a interação e afinidade com os receptores e com sua atividade intrínseca. O receptor $\mu 1$ é relacionado com analgesia espinhal e supra-espinhal, hipotermia e liberação de prolactina. O receptor $\mu 2$ é relacionado a depressão respiratória, bradicardia e redução da motilidade intestinal. Ambos os receptores são relacionados a euforia, dependência e miose. O receptor $\delta$ é relacionado a depressão respiratória, adição, hipotensão arterial, hipertermia e resposta a toxinas. O receptor $\mathrm{k}$ relaciona-se com analgesia espinhal, sedação e miose, enquanto que o receptor $\zeta$ relaciona-se à disforia, alucinações, midríase, taquicardia e hipertensão arterial. Já o receptor $\xi$ está associado ao estresse ${ }^{2,3}$.

Os opióides produzem alívio seletivo da dor, sem afetar a consciência, desde que se use dose adequada. A analgesia é conseqüência de ação em diferentes níveis do sistema nervoso central (SNC) e periférico. Na medula espinhal inibema transmissão do influxo nociceptivo, provavelmente por sua atuação sobre as terminações pré-sinápticas, impedindo a liberação de neurotransmissores excitatórios, como a substância P. Na região supra-medular atuam estimulando sistemas analgésicos descendentes de características inibitórias sobre a transmissão nociceptiva medular. Esses diferentes sítios de ação explicam a resposta diferenciada, dose dependente, de determinados opióides, como é o caso da morfina ${ }^{4}$.

A analgesia produzida pelos opióides é quantitativa e qualitativamente diferenciada de acordo com a capacidade de cada fármaco em estimular os receptores $\mu, \mathrm{K}, \delta$ e $\xi$. As drogas que agem sobre os receptores $\mu$, como a morfina, possuem efeitos analgésicos praticamente ilimitados, podendo, em doses elevadas, aliviar qualquer tipo de dor. Os fármacos que agem basicamente no receptor $\mathrm{k}$ têm efeito analgésico limitado, chamado efeito teto, que não aumenta proporcionalmente com a dose; portanto, possuem um grau moderado de atividade analgésica e são capazes de antagonizar os opióides ${ }^{5}$.

Opióides são utilizados rotineiramente para administração raquidiana e quando comparada ao uso sistêmico, estão associados a menor incidência de efeitos colaterais, necessidade de menores doses e à maior duração de ação. Isto ocorre porque a administração subaracnóidea permite o acesso maior e direto ao receptor.

A maioria dos opióides pode ser administrada por via subaracnóidea; contudo, as suas propriedades físico-químicas, peso molecular e lipossolubilidade, a sua afinidade intrínseca pelos receptores opióides e a sua farmacocinética determinarão a eficácia analgésica, a incidência e a intensidade dos efeitos indesejáveis.

A seleção de um opióide é baseada na sua lipossolubilidade. Os opióides lipossolúveis difundem-se prontamente através das membranas e medula espinhal, produzindo início rápido de analgesia. Os opióides hidrossolúveis atravessam estes tecidos mais lentamente e portanto têm início de ação mais tardio. Contudo, quanto mais lipossolúvel o opióide for, maior probabilidade tem de ser absorvido pelos vasos e pela gordura ou sítios receptores inespecíficos. Assim, esses agentes têm duração de ação inversamente proporcional à sua lipossolubilidade. Agentes hidrossolúveis permanecem mais tempo no líquido cefalorraquidiano e migram lentamente para níveis mais altos no canal medula. O tempo de analgesia pode variar de 4-6 horas para o sufentanil, chegando a atingir 24 horas no caso da morfina. 
Os fármacos hidrossolúveis, como a morfina, têm papel já estabelecido na infusão contínua, porém opióides lipossolúveis também podem ser utilizados porvia intra-raquidiana de forma continuada. Estudos têm sido realizados com o uso de fentanil e sufentanil, demonstrando que estes medicamentos podem ter papel de destaque no tratamento de síndromes dolorosas localizadas, quando o cateter élocado na proximidade da substância gelatinosa, na raiz nervosa correspondente à região afetada pela dor ${ }^{6-10}$.

As doses dos opióides para infusão subaracnóidea contínua ainda não estão bem estabelecidas, entretanto, observa-se que bolus de opióides podem ser utilizados para controle da dor com boa resposta (Tabela I).

Tabela I - Doses de Opióides para Uso Subaracnóideo em Analgesia ${ }^{80}$

\begin{tabular}{lccc}
\hline Opióide & $\begin{array}{c}\text { Dose em } \\
\text { bolus }(\mathrm{mg})\end{array}$ & $\begin{array}{c}\text { Início de } \\
\text { Ação (min) }\end{array}$ & $\begin{array}{c}\text { Duração da Dose } \\
\text { de bolus (h) }\end{array}$ \\
\hline Morfina & $0,1-0,3$ & 15 & $8-24$ \\
Meperidina & $10-30$ & - & $10-24$ \\
Sufentanil & $0,001-0,005$ & $4-10$ & $2-4$ \\
Fentanil & $0,005-0,025$ & 5 & $3-6$ \\
\hline
\end{tabular}

Aadministração subaracnóidea de opióides, apesar de relativamente recente, geralmente está associada ao controle total dos sintomas álgicos. Apesar da elevada efetividade destes agentes, alguns pacientes têm resposta insatisfatória ao tratamento ou desenvolvem tolerância e intolerância ao medicamento, o que motivou a busca de novos agentes adjuvantes.

\section{ANESTÉSICOS LOCAIS}

(lidocaína, bupivacaína e ropivacaína)

Ahistória da aplicação dos anestésicos locais $(A L)$ por via espinhal é bastante antiga, sendo o seu uso inicialmente documentado por Bier em 1899. Em 1940, Lemmon introduziu a idéia de infusão contínua de anestésico e, em 1948, Lofgren apresentou sua tese, defendendo o uso de lidocaína espinhal, o que deu início à aplicação dessa substância para procedimentos cirúrgicos ${ }^{11-13}$.

Os AL tais como a lidocaína, a bupivacaína e, mais recentemente, a ropivacaína têm papel definido no controle de pacientes com dor. Eles agem inativando os canais de sódio voltagem-sensíveis. Sua ação farmacológica depende de características físico-químicas como peso molecular, lipossolubilidade, grau de ionização e afinidade protéica ${ }^{14}$. Observa-se que a lipossolubilidade determina a potência analgésica; o pka, o início do bloqueio; e a afinidade protéica a duração da analgesia. Os AL combinam-se com o receptor protéico localizado no canal de sódio da membrana nervosa. Compostos que possuem maior afinidade se ligam mais firmemente aos sítios receptores, permanecem no canal por período de tempo maior e apresentam bloqueio de condução mais longo ${ }^{15}$.
As diferenças entre resultados in vitro e in vivo parecem estar relacionadas às propriedades vasodilatadoras ou à difusibilidade tecidual dos diversos AL. A lidocaína provoca maior vasodilatação que a bupivacaína, implicando maior absorção vascular ${ }^{14}$. O tempo de latência do bloqueio de condução depende de alguns fatores tais como a capacidade de difusão através de tecidos não nervosos e a concentração do anestésico empregado.

O efeito eletrofisiológico predominante dos anestésicos locais ocorre durante a fase de despolarização do potencial de ação. Ocorre decréscimo na velocidade e no grau de despolarização, de tal forma que o limiar de excitabilidade para a transmissão não é mais atingido e o impulso nervoso deixa de ser propagado ao longo do nervo.

Alguns autores acreditam que o efeito sobre o fluxo de sódio seja mediado via interação cálcio-AL. Aumentando-se ou reduzindo-se a concentração do íon cálcio ao redor do nervo, pode-se antagonizar ou potencializar o bloqueio analgésico, respectivamente, o que sugere uma competição entre o ALe o cálcio ligado à membrana ${ }^{16}$.

Os AL podem ser utilizados através de bloqueio regional ou por administração sistêmica e são considerados efetivos no tratamento da dor de origem nociceptiva ou neuropática ${ }^{17}$. Entretanto, a sua aplicação está relacionada à presença de efeitos indesejados como tolerância, retenção urinária, parestesia, hipotensão ortostática, bradipnéia e dispnéia. Estes fármacos podem ser administrados isoladamente ou associados a opióides. Tal combinação proporciona melhor qualidade de analgesia com menor incidência de efeitos indesejáveis.

As doses espinhais habitualmente aplicadas são diferenciadas de acordo com a droga utilizada (Tabela II). Contudo, é comum a necessidade de variação na concentração e na taxa de infusão, o que dificulta o uso dos anestésicos locais em bombas de infusão subaracnóideas pré-programadas.

Tabela II - Doses de Anestésicos Locais para Uso Subaracnóideo em Analgesia

\begin{tabular}{lccc}
\hline Anestésico & $\begin{array}{c}\text { Dose } \\
\text { bolus }(\mathrm{mg})\end{array}$ & $\begin{array}{c}\text { Início de } \\
\text { Ação }(\mathrm{min})\end{array}$ & $\begin{array}{c}\text { Duração da Dose } \\
\text { de bolus }(\mathrm{h})\end{array}$ \\
\hline Lidocaína & $50-100$ & $10-15$ & $30-50$ \\
Bupivacaína & $7-15$ & $<1 \mathrm{~min}$ & $3-4$ \\
Ropivacaína * & - & - & - \\
\hline
\end{tabular}

* Não descrita dose em humanos

\section{AGONISTAS $\alpha_{2}$-ADRENÉRGICOS (cocaína e clonidina)}

Mecanismos $\alpha_{2}$-adrenérgicos de analgesia têm sido explorados há mais de cem anos. Acocaína, o primeiro anestésico aplicado por via espinhal, produz analgesia primariamente por sua ação como anestésico local, mas também inibe a recaptação de norepinefrina. A analgesia espinhal produzida pela cocaína deve-se, em parte, à estimulação noradrenérgica de receptores $\alpha_{2}$. Esta descoberta motivou a utilização de agonistas $\alpha_{2}$-adrenérgicos com o intuito de obter-se anal- 
gesia. Entretanto, só em 1984, a clonidina foi administrada com sucesso, quando Tamsen e col. ${ }^{18}$, após testes de neurotoxicidade em animais, injetaram esta substância no espaço peridural de dois doentes com dor crônica. Isto possibilitou a realização de estudos posteriores que demonstraram a segurança da clonidina subaracnóidea no tratamento de síndromes dolorosas.

$\mathrm{Na}$ atualidade, a clonidina subaracnóidea é utilizada em associação com outras drogas para o tratamento da dor de difícil controle. A clonidina subaracnóidea é efetiva no acompanhamento da dor do câncer refratária, no manuseio da síndrome dolorosa complexa regional (SDCR) e no controle da dor pós-operatória, prolongando os efeitos dos anestésicos locais e potencializando a efetividade de outros agentes de uso no neuroeixo.

A ação analgésica da clonidina é decorrente de sua atuação em receptores $\alpha_{2}$-agonistas localizados em nível periférico, espinhal e/ou cerebral. Ela pode ser utilizada por diferentes vias, sendo mais potente após administração neuroaxial, quando comparada com administração sistêmica. Avaliando-se a analgesia com iguais doses de clonidina administrada em cada via, observa-se que sua injeção subaracnóidea em pequenas doses, $150 \mu \mathrm{g}$, após cesariana e cirurgias ortopédicas de pequeno porte, produz analgesia por 4 a 6 horas, enquanto a injeção das mesmas doses por via muscular produz analgesia semelhante ao placebo ${ }^{19,20}$. Analisando-se a administração peridural e venosa de clonidina em grandes doses, verifica-se que a clonidina peridural produz analgesia de melhor qualidade, estando associada à menor necessidade de opióide ${ }^{21,22}$. Alguns estudos têm demonstrado quea clonidina subaracnóidea é mais potente que a peridural, principalmente no que concerne ao tratamento da dor aguda. Eisenach e col. ${ }^{23}$ demonstraram que a clonidina por via subaracnóidea é dez vezes mais potente que a peridural para o tratamento da dor pós-operatória, e duas vezes mais efetiva no controle da dor neuropática.

Aclonidina subaracnóidea produz analgesia por aumentar a liberação de noradrenalina espinhal, a qual tem papel importante no sistema descendente inibitório da dor ${ }^{24}$. Embora este agente tenha uma ação por estimulação noradrenérgica, trabalhos recentes têm demonstrado que a analgesia das drogas noradrenérgicas é, em parte, decorrente da ativação de neurônios colinérgicos espinhais. Estudos anatômicos mostram a presença de elevada densidade de receptores muscarínicos e $\alpha_{2}$-adrenérgicos em áreas superficiais da coluna dorsal ${ }^{25}$, e estudos funcionais em animais indicam a existência de efeitos antinociceptivos de agonistas diretos destes receptores após sua administração por via subaracnóidea ${ }^{26}$. Esta interação é sugerida pela potencialização da ação antinociceptiva de agonistas $\alpha_{2}$-adrenérgicos subaracnóideos, quando associados a inibidores da colinesterase, como a neostigmina ${ }^{27}$ e pela inibição deste efeito por injeção subaracnóidea de antagonistas muscarínicos como a atropina ${ }^{28}$. Além disto, a administração de agonistas $\alpha_{2}$-adrenérgicos, em doses capazes de produzir antinocicepção em oveIhas, aumenta a concentração de acetilcolina no fluido cérebro-espinhal, um efeito que é potencializado pela fisostigmi- na e bloqueado por antagonistas $\alpha_{2}$-adrenérgicos como o idazoxan ${ }^{29}$. Isto tudo sugere que a clonidina exerça sua ação analgésica através de diferentes mecanismos, ou seja, pelo bloqueio da condução nervosa das fibras $\mathrm{C}$ e $\mathrm{A} \delta^{30}$, pelo aumento da concentração de acetilcolina medular, e pela elevação dos níveis de noradrenalina no sistema nervoso central ${ }^{31}$, contribuindo para melhor analgesia dos opióides e anestésicos locais.

Estudos que avaliam a aplicação da clonidina espinhal demonstram que a dose de $15 \mathrm{a} 45 \mu \mathrm{g}$ é suficiente para auxiliar a analgesia em procedimentos ortopédicos ${ }^{32}$, e que a infusão contínua subaracnóidea de 2 a $30 \mu \mathrm{g} \cdot \mathrm{h}^{-1}$ é efetiva para o tratamento de dor crônica associada à síndrome dolorosa complexa regional ${ }^{33}$. Entretanto, deve-se estar atento para o fato de que nas preparações de clonidina comercialmente disponíveis, a concentração encontrada é de $150 \mu \mathrm{g} \cdot \mathrm{ml}^{-1}$, o que implica a necessidade de $2 \mathrm{ml}^{\text {. dia }}{ }^{-1}$ para a obtenção de analgesia efetiva. Esta taxa de infusão dificulta o uso deste agente na prática clínica, já que as bombas de infusão subaracnóidea pré-programadas geralmente liberam 0,15 a $0,5 \mathrm{ml}$ da solução ao dia ${ }^{34}$.

A clonidina subaracnóidea é promissora como adjuvante no tratamento da dor, porém seu uso clínico tem sido limitado pela presença de efeitos indesejáveis, especialmente, hemodinâmicos e sedação. A dexmedatomidina, um novo agonista $\alpha 2$ seletivo, tem sido estudada e parece estar relacionada a resultados clínicos promissores, com menores efeitos adversos quando utilizada por via subaracnóidea.

\section{ANTAGONISTA DOS AMINOÁCIDOS EXCITATÓRIOS (cetamina)}

Os aminoácidos excitatórios (AAE) têm papel chave na transmissão nociceptiva. O glutamato e o aspartato são os principais neurotransmissores excitatórios das vias de transmissão somatossensoriais e estão presentes nos nervos periféricos, gânglios e axônios da raiz dorsal e células do corno posterior, onde se ligam a receptores específicos. Existem vários receptores nas unidades neuronais do corno posterior da medula espinhal (CPME). Dentre eles destacam-se os receptores N-metil-D-Aspartato (NMDA) e os não-NMDA. Há dois subtipos de receptores não-NMDA, o ácido alpha-amino-3-hidroxi-5-metilisoxazole-4-propiônico (AMPA) e o cianato, os quais são ativados logo após a liberação dos AAE e estão envolvidos no mecanismo de localização têmporo-espacial e na quantificação da dor. Os receptores NMDA, quando ativados, contribuem para o mecanismo de sensibilização dos neurônios do CPME, influenciando na geração da dor crônica e na modulação da nocicepção. Muitos neurônios sensitivos do CPME são ativados por estímulos mecânicos, térmicos e nociceptivos. Esta estimulação aumenta a excitabilidade dos neurônios do CPME e leva à ativação de sinapses NMDA previamente inativas, com conseqüente hiperalgesia secundária e alodinia. A persistência do estímulo doloroso torna os neurônios do CPME sensibilizados devido à fosforilação dos receptores ${ }^{35}$. 
Normalmente, a remoção do agente nociceptivo resulta em desaparecimento da hiperalgesia e alodínea, o que ocorre em horas ou dias. Entretanto, a estimulação nociceptiva prolongada pode resultar em persistência do fenômeno doloroso, mesmo após a remoção do agente causador, em decorrência da estruturação dos mecanismos de sensibilização dos neurônios do CPME. Este seria um dos mecanismos da ocorrência da dor crônica. Admite-se que o emprego de antagonistas de receptores NMDA possa bloquear o fenômeno de sensibilização e de cronificação de síndromes álgicas ${ }^{36}$.

O receptor NMDAé um subtipo dos receptores do glutamato, classificado de acordo com critérios farmacológicos, pelo seu agonista seletivo o N-metil-D-aspartato. Tem características ionotrópicas, incorporando na sua estrutura um local de ligação do transmissor a um canal catiônico específico, formado por vários subtipos de proteínas. A ativação do receptor NMDAé do tipo voltagem-dependente e a ação de neuropeptídeos leva à despolarização da membrana celular do mesmo, libertando o magnésio do canal iônico e aumentando a sensibilidade para o glutamato e o influxo de cálcio para o interior da célula. Estas alterações na membrana irão iniciar uma série de eventos que alteram a resposta neuronal a estímulos subseqüentes, culminando nos fenômenos chamados de wind-up, ou seja, o aumento gradual da resposta nervosa, tanto em magnitude como duração, a estímulos repetidos na fibra C. O magnésio, em concentrações fisiológicas bloqueia o receptor impossibilitando a ligação dos AAE no seu sítio específico. Entretanto, a administração de antagonistas dos receptores não-NMDA, mesmo em doses elevadas, não afeta a transmissão da dor.

Muitos estudos têm focalizado a utilização de antagonistas dos receptores NMDA para o controle e redução do desenvolvimento dos fenômenos de wind-up. Uma dessas formas é o uso de opióides em altas doses que tem a capacidade de inibir o fenômeno de wind-up. Chapman e col. ${ }^{37}$, demonstraram que opióides e antagonista-NMDA trabalham sinergicamente na inibição da nocicepção. Segundo Ma e col. ${ }^{38}$, o uso subaracnóideo de antagonistas-NMDA previne e reverte a dor induzida pelo tato em ratos. Similarmente, Yamamoto e col. ${ }^{39}$ concluíram que receptores NMDA têm papel no desenvolvimento de estados hiperestésicos subseqüentes à lesão em nervos. Eles observaram que antagonistas NMDA subaracnóideos, em baixas doses, abolem temporariamente esta hiperestesia.

O primeiro passo para a utilização subaracnóidea de antagonistas NMDA em humanos foi dado por Kristensen e col. ${ }^{39}$. Eles estudaram os efeitos do uso subaracnóideo de fenciclidina (CPP) em ratos com o intuito de determinar sua potencial neurotoxicidade, não tendo sido observada diferença entre a CPP e solução fisiológica. Este estudo também descreveu um caso clínico em que CPP foi administrada por via subaracnóidea, em um paciente com dor neurogênica intratável em membros inferiores, associada à hiperalgesia secundária. Esta foi aliviada com o uso da CPP.

Acetamina tem sido utilizada em humanos por via subaracnóidea. Extensas pesquisas foram realizadas no passado, mas limitadas pela potencial neurotoxicidade do medicamento. Recentes estudos em animais falharam em demonstrar anormalidades no cordão espinhal após uso de cetamina com conservante. Yang e col. ${ }^{40}$ demonstraram que a cetamina subaracnóidea aumenta o efeito analgésico de opióides em pacientes com doença de etiologia oncológica. Limitações ao uso subaracnóideo incluem os seus bem descritos efeitos psicotrópicos, e os de vômito, dormência, hipertensão arterial, taquicardia e, raramente, depressão cardiovascular.

O uso de antagonistas NMDA tem-se mostrado como alternativa terapêutica para o manuseio da dor do câncer e da dor neuropática crônica. As doses freqüentemente preconizadas variam de acordo com a via de administração: bolus venoso ou peridural de $1 \mathrm{mg} \cdot \mathrm{kg}^{-1}$, seguido de infusão contínua inferior a $20 \mu \mathrm{g} \cdot \mathrm{kg} \cdot \mathrm{min}^{-141}$; a dose para administração subaracnóidea ainda não foi estabelecida. Novos estudos necessitam ser realizados com o intuito de estabelecer a dose ideal, já que, apesar dos efeitos analgésicos serem bem documentados, estão associados a efeitos indesejáveis importantes.

\section{AMINOÁCIDOS INIBITÓRIOS (benzodiazepínicos e baclofen)}

O ácido gama-aminobutírico (GABA) e a glicina são aminoácidos inibitórios ( $\mathrm{AAl}$ ) que agem como neurotransmissores no sistema nervoso central ${ }^{42,43}$. Receptores GABA estão presentes nos funículos dorsal e lateral, no trato de Lissauer e nas lâminas I, II e III de Rexed. Três tipos de receptores GABA têm sido identificados: GABA-A, GABA-B e GABA-C 44. O receptor GABA-Aé parte de um complexo iônico com o cloro ${ }^{45}$, possuindo, como agonista, o muscimol e, como antagonista seletivo, a gabazina. Barbitúricos e álcool modulam a atividade deste receptor por facilitação direta do influxo de cloro ${ }^{46}$. Benzodiazepínicos ligam-se a um sítio específico no complexo receptor-GABA-A, facilitando a ligação receptor GABA-agonista e aumentando o tempo de abertura do canal iônico ${ }^{47}$. O receptor GABA-B, complexo de ligação com a proteína-G, quando ativado aumenta o efluxo de potássio ${ }^{44}$. O baclofen é um agonista seletivo GABA-B e o faclofen é um antagonista seletivo. Mais recentemente, especula-se sobre um receptor GABA-C, o qual é também diretamente associado a canais de potássio. $O$ ácido cis-4-aminocrotônico é um agonista seletivo do receptor GABA-C. Não há antagonista seletivo conhecido até o presente momento.

Ambos, agonistas GABA-A e GABA-B, têm propriedades analgésicas após administração subaracnóidea em modelos de dor crônica. Serrao e col. ${ }^{48}$ demostraram que o midazolam subaracnóideo, um agonista GABA-A, foi efetivo no tratamento de dor mecânica da região lombar. Borg e col. ${ }^{49}$ obtiveram excelentes resultados com o uso subaracnóideo de midazolam e clonidina em quatro pacientes com dor crônica. Após estudos em animais realizados em 1980, foram originalmente atribuídas propriedades antinociceptivas ao midazolam subaracnóideo. Finalmente em 1986, o midazolam foi administrado a seres humanos, e então se demonstrou que a analgesia deve-se à ação sobre os receptores GABA-A e sobre receptores $\mu \mathrm{e} \kappa$, presentes nas vias transmissoras Vol. 52, N 5, Setembro - Outubro, 2002 
da dor ${ }^{50}$. Estudos evidenciam que pacientes portadores de síndromes dolorosas refratárias, quando submetidos à administração subaracnóidea de midazolam, experimentam analgesia singular, dose e concentração dependentes. Doses únicas em pacientes virgens desta abordagem promovem analgesia que inicia com 4 a 5 minutos, com persistência de alívio por 5 a 8 dias. Pacientes com sistemas subaracnóideos implantados para liberação de fármacos podem solicitar bolus de $0,83 \mu \mathrm{g}$ a cada seis, oito ou doze horas, o que, em função da pouca dispersão cranial, está associado à ocorrência de poucos efeitos colaterais ${ }^{80}$.

Taira e col. ${ }^{51}$ constataram a eficácia analgésica de agonistas GABA espinhal através do uso subaracnóideo de baclofen, um relaxante muscular de ação central, agonista GABA-B, em pacientes com dor central após acidente cérebro-vascular. Herman e col. ${ }^{52}$ demonstraram o efeito analgésico do baclofen subaracnóideo em pacientes com lesão no cordão espinhal relacionada à espasticidade e dor disestésica e, por tal efeito, tem sido indicado com freqüência para o controle da dor associada à espasticidade. Albright e col. ${ }^{53}$ e Penn e col. ${ }^{54}$ demonstraram redução do tônus muscular e espasmo em $97 \%$ dos pacientes. Como resultado da redução da espasticidade, outros benefícios freqüentemente ocorreram, tais como redução da dor, melhora do sono, da função intestinal e da bexiga, o que implicou em melhora da qualidade de vida. O implante de bomba subaracnóidea pré-programada tem sido utilizado para a liberação do baclofen no tratamento de espasticidade intensa. Recentes publicações ${ }^{54,55}$ têm demonstrado que o uso espinhal de baclofen é seguro e eficaz quando aplicado com estes fins, não estando associado a alterações histopatológicas ou neurotoxicidade fisiológica. Em estudo realizado por Satoh e col. ${ }^{56}$ observou-se que o baclofen subaracnóideo tem ação no controle da dor neuropática. As doses preconizadas para este fim são de 25 a $75 \mu \mathrm{g} \mathrm{em}$ bolus, seguidas de uma infusão contínua de 3 a $8 \mu \mathrm{g} \cdot \mathrm{h}^{-1}$. Entretanto, a administração isolada deste fármaco não é suficiente para o controle total dos sintomas, sendo necessária a associação com outros tipos de agentes de uso oral, como os anticonvulsivantes, os antidepressivos, os opióides e os antiinflamatórios ${ }^{80}$

\section{ACETILCOLINA E INIBIDORES DA ACETILCOLINESTERASE (neostigmina)}

A acetilcolina é um potencial analgésico da família das monoaminas. Terminais colinérgicos são abundantes no sistema nervoso central, principalmente no núcleo da rafe, núcleo ambíguo, no núcleo motor do vago e em neurônios localizados na coluna dorsal. Receptores colinérgicos nicotínicos e muscarínicos estão presentes na coluna espinhal e a administração de agonistas destes receptores produz analgesia em uma série de estudos animais. Trabalhos demonstram que este efeito é aditivo ao da morfina ${ }^{57,58}$, sendo decorrente da ação de agonistas colinérgicos em múltiplos sítios.

A administração espinhal de inibidores da acetilcolinesterase, tais como o neostigmina, inibe a degradação de neuro- transmissores endógenos presentes na medula, induzindo analgesia. A liberação de acetilcolina no cordão espinhal é estimulada pela dor, pelo uso de opióides sistêmicos e pelos agonistas $\alpha_{2}$-adrenérgicos subaracnóideo ${ }^{59}$. Além disto, o efeito analgésico de acetilcolina parece envolver a estimulação da produção de óxido nítrico, já que o aumento dos níveis deste no cordão espinhal é observado após administração subaracnóidea de acetilcolina ${ }^{59}$. Em estudos preliminares conduzidos em pacientes voluntários, neostigmina subaracnóidea promove analgesia em doses que variam de 10 a 50 $\mu \mathrm{g}{ }^{60}$. Doses de neostigmina superiores a $100 \mu \mathrm{g}$ causam náusea e fraqueza em extremidades inferiores, porém a aplicação das mesmas não implica uma maior incidência de sedação, prurido, depressão respiratória ou alteração hemodinâmica ${ }^{61}$. De fato, neostigmina espinhal aumenta a atividade de neurônios simpáticos, contrapondo os efeitos simpaticolíticos dos anestésicos locais e agonistas $\alpha_{2}$-adrenérgicos ${ }^{62}$, prevenindo hipotensão. Gordh e col. ${ }^{63}$ observaram que a analgesia da clonidina subaracnóidea é aumentada pela neostigmina de maneira sinérgica. Estes autores postularam que agonistas $\alpha_{2}$-adrenérgicos, quando administrados por via subaracnóidea, causam analgesia em parte pela ativação de neurônios espinhais colinérgicos. Em adição, agonistas muscarínicos subaracnóideos ou neostigmina aumentam a pressão arterial e a freqüência cardíaca, por ação em neurônios simpáticos pré-ganglionares. Autilização conjunta de neostigmina e clonidina combate a hipotensão arterial induzida pela clonidina em ovelhas. É possível, portanto, que isto ocorra também em humanos, implicando benefício para o paciente ${ }^{64}$, entretanto, a regulação temporal pode vir a ser um problema, já que o efeito hipertensivo da neostigmina parece ser tardio em comparação com o início mais rápido do efeito hipotensor da clonidina e dos anestésicos locais ${ }^{60}$. Os inibidores da colinesterase têm-se mostrado como medicamentos adjuvantes promissores para o tratamento da dor aguda e crônica, porém a elevada incidência de efeitos colaterais e a incerteza acerca da dose efetiva, têm-se mostrado como empecilho para o uso clínico deste fármaco. A descoberta de elementos que combatam os seus efeitos adversos é desejada e pode implicar benefícios para a prática diária.

\section{BLOQUEADORES DOS CANAIS DE CÁLCIO (diltiazen, nimodipina e verapamil)}

O influxo e efluxo de cálcio nas células do cordão espinhal é importante para a função neuronal. A liberação de neurotransmissores excitatórios é aclopada com ativação de canais de cálcio voltagem-dependente. Portanto, o íon cálcio é essencial para a regulação da excitabilidade neuronal e para a liberação de neurotransmissores, com posterior despolarização sináptica. Quatro tipos de canais de cálcio foram identificados em gânglios e neurônios da raiz dorsal: L, N, T e P. Destes, apenas o canal $P$ não está envolvido com a regulação da excitabilidade neuronal.

A administração subaracnóidea de conapeptídeos, antagonistas dos canais de cálcio tipo T, alivia a dor neuropática em 
ratos ${ }^{65}$, atenuando ambas as fases do teste de formalina e prevenindo o desenvolvimento de hiperalgesia induzida pela capsaicina. Entretanto, pronunciados distúrbios motores persistiram por dois a três dias após administração de conatoxina.

Os antagonistas de canais de cálcio, diltiazem e nimodipina têm propriedades clínicas analgésicas. O uso de verapamil em combinação com analgésicos já consagrados como a morfina, tem se mostrado como uma grande promessa para o futuro ${ }^{66}$. Opióides inibem a nocicepção através do bloqueio de canais de cálcio voltagem-dependente e da ativação de proteínas G. Portanto, é provável que a inibição de condutância dos canais de cálcio promova analgesia ou, pelo menos, aumente a qualidade da analgesia dos opióides.

\section{Adenosina}

O nucleotídeo trifosfato de adenosina (ATP) é parte de cada célula que compõe o corpo humano e tem papel vital no metabolismo celular. O ATP extracelular e seu metabólito, a adenosina, tem efeito pronunciado em vários processos biológicos, tais como metabolismo hepático do glicogênio, contração muscular, função cardíaca, função plaquetária e neurotransmissão. O efeito da adenosina é mediado através de dois subtipos de receptores celulares superficiais, o receptor $\mathrm{A} 1$ e o receptor $\mathrm{A} 2$. O subtipo $\mathrm{A} 1$ está envolvido na modulação da transmissão espinhal da dor e o seu efeito se dá através da inibição da atividade da adenilciclase, resultando na redução do influxo de cálcio pré-sináptico e/ou na inibição da imunorreatividade da substância P. Administração subaracnóidea de adenosina tem sido utilizada com algum sucesso para o tratamento de dor neuropática crônica. Entretanto, o seu uso está associado ao aumento da incidência de lombalgia ${ }^{67}$, mostrando ainda uma desvantagem que é a necessidade de infusão contínua, já que sua meia vida é curta. De qualquer modo, o papel da adenosina no controle da dor crônica de difícil controle é bastante complexo. Novos estudos necessitam ser realizados para que esta substância possa ser utilizada com maior segurança na prática clínica.

\section{Serotonina}

Aserotonina ( $5 \mathrm{HT}$ ) é uma monoamina envolvida na estimulação das vias descendentes de controle da dor. Ela está presente no corno dorsal medular, primariamente na lâmina l e II de Rexed e na porção ventral da medula. Estudos têm demonstrado que a estimulação de áreas relacionadas à analgesia está associada à elevação dos níveis de serotonina ${ }^{68}$. O sistema inibitório descendente da dor consiste em diversas conexões anatômicas centrais, iniciando pela substância cinzenta periaqueductal, que por sua vez recebe aferências de muitos núcleos diencéfálicos como o núcleo parafascicular talâmico, o núcleo pré-mamilar dorsal, a zona incerta, os núcleos dorsomedial e ventromedial do hipotálamo, o núcleo arqueado e o tronco encefálico. A substância cinzenta periaqueductal envia projeções para o núcleo paragigantocelular e núcleo magno da rafe (NMR). O NMR envia fibras serotoninérgicas que se projetam através do funículo dorsolateral para o corno dorsal da medula nas lâminas I, II e IV, onde inibem seletivamente neurônios nociceptivos, incluindo interneurônios e neurônios dos tratos ascendentes. Aestimulação elétrica do NMR aumenta a liberação de serotonina no corno dorsal da medula, efeito esse bloqueado pelo pré-tratamento com $p$-clorofenilalanina ( $\mathrm{pCPA}$ ), um antagonista serotoninérgico. Do mesmo modo, o estímulo nóxico aumenta a produção do ácido 5-hidroxiindolacético, um metabólito da serotonina ${ }^{69,70}$.

Muitos fármacos de uso consagrado na prática clínica têm ação analgésica por atuação sobre o sistema serotoninérgico. Apesar das evidências, os resultados práticos têm sido contraditórios. Mjellem e col. ${ }^{71}$ demonstraram que a ativação de receptores 5-HT produz analgesia. Entretanto, Fozard em 1984 e Richardson e col. ${ }^{72,73}$, em 1985, observaram efeito nóxico da serotonina quando administrada perifericamente, porém um efeito antinociceptivo quando administrada no neuroeixo. Investigações futuras são necessárias para esclarecer o verdadeiro papel da serotonina no controle do estímulo álgico.

\section{ANTIDEPRESSIVOS TRICÍCLICOS (amitriptilina)}

Os antidepressivos tricíclicos (ADT) são medicamentos já consagrados no tratamento da dor crônica. O seu papel na modulação da dor está documentado no que diz respeito a sua ação sobre a recaptação da serotonina e da noradrenalina, substâncias que estão envolvidas na inibição da transmissão do estímulo álgico. Estudos in vitro têm demonstrado ação dos ADTs nos receptores NMDA ${ }^{74,75}$, o que explicaria com mais clareza o controle de sintomas que acompanham a dor neuropática, tais como a alodínea e a hiperalgesia.

Estudos em animais têm demonstrado que o uso subaracnóideo de ADTs revertem a hiperalgesia e que o mecanismo envolvido no controle da dor é semelhante àquele visto com a utilização de antagonistas de receptores NMDA. Eisenach e col. ${ }^{76}$ demonstraram a reversão da hiperalgesia NMDA-induzida após a administração de amitriptilina por via subaracnóidea. Observaram que o mecanismo envolvido não é relacionado à inibição da recaptação de monoaminas, já que a utilização de fentolamina não reverte os efeitos dos ADTs sobre a dor neuropática e conseqüentemente, sobre a hiperalgesia e alodinia dela decorrentes. Segundo os mesmos autores, a amitriptilina subaracnóidea tem efeito sinérgico ao da morfina quando esta é administrada por via venosa. No momento, a aplicação subaracnóidea dos ADTs na prática clínica tem sido dificultada pela inexistência de preparações livres de conservantes e pela observação de efeitos indesejáveis em ratos, tal como a fraqueza muscular. Os bons resultados obtidos em estudos animais reforçam a importância de se buscar substâncias capazes de serem utilizadas por esta via. 
INIBIDORES DA SÍNTESE DE PROSTAGLANDINA (cetorolaco)

As prostaglandinas e os leucotrienos são sintetizados a partir do ácido aracdônico, através da ação da ciclooxigenase e da lipoxigenase, respectivamente. A prostaglandina e o leucotrieno têm papel importante na sensibilização de fibras aferentes primárias periféricas e na geração da hiperalgesia primária. Entretanto, a prostaglandina tem também importância nos mecanismos centrais de transmissão da dor na coluna dorsal. O influxo de cálcio para o neurônio e células da glia, após a estimulação dos nociceptores, ativa a fosfolipase A2 e quebra o ácido aracdônico. O ácido aracdônico é quebrado pela ciclooxigenase tipo $2 \mathrm{em}$ nível central e pela ciclooxigenase tipo 1 em nível periférico, dando origem à prostaglandina. Os efeitos da prostaglandina na transmissão da dor são mediados pelo aumento neuronal dos níveis de cálcio e AMPcíclico, talvez aumentando a excitabilidade e a liberação de neurotransmissores e neuromoduladores. Acredita-se que estas reações sejam estimuladas por receptores NMDA.

Autilização de inibidores da ciclooxigenase por via subaracnóidea tem sido proposta para o controle da dor crônica. Malmberg e col. ${ }^{77}$ demonstraram que cetorolaco subaracnóideo inibe o desenvolvimento de hiperalgesia. Entretanto, este analgésico não opióide tem efeito limitado no controle da dor aguda. Opióides sozinhos produzem supressão dose-dependente de ambas as fases, aguda e crônica. Quando dado em conjunto com morfina, o cetorolaco produz efeito antinociceptivo sinérgico. O cetorolaco também tem sinergismo com agonistas $\alpha_{2}$-adrenérgicos. Antes da introdução desta medicação subaracnóidea na prática clínica são necessários estudos que afastem possível neurotoxicidade e efeitos indesejáveis.

\section{POSSÍVEIS DROGAS PARA UTILIZAÇÃO FUTURA}

Os inibidores da síntese de óxido nítrico têm se mostrado como uma promessa para o controle da dor crônica. Sabe-se que o óxido nítrico tem papel na transmissão sensorial e que a sua síntese é estimulada pelo aumento do cálcio intracelular após abertura dos receptores NMDA. Estudos têm demonstrado que o óxido nítrico está envolvido com o desenvolvimento do fenômeno de wind-up e vários modelos de hiperalgesia ${ }^{78}$. A administração subaracnóidea de análogos da arginina, um inibidor da síntese de óxido nítrico, produz redução dose-dependente da hiperalgesia resultante de lesão nervosa ${ }^{79}$.

Colecistocinina (CCK), importante regulador da função gastrointestinal e neurotransmissor do sistema nervoso central, tem papel na transmissão da dor. Acredita-se que o uso de agonistas específicos de receptores CCK-B bloqueie a indução, mas não a manutenção da sensibilização central.

A substância $P$ pertence à família das taquicininas e encontra-se localizada tanto em nível central, substância gelatinosa e neurônios do CPME, quanto periférico. Ela liga-se a receptores NK1 e encontra-se associada à transmissão e mo- dulação da informação nociceptiva. Acredita-se que o uso de antagonistas da substância P por via subaracnóidea possa ter propriedades antinociceptivas. O uso de capsaicina por via subaracnóidea implica redução acentuada da substância $\mathrm{P}$ na raiz dorsal. Entretanto, está associada à degeneração de aferentes mielinizados.

\section{CONCLUSÕES}

O tratamento das condições dolorosas, agudas e crônicas, mostrou avanço extraordinário nas últimas décadas. AMedicina tem possibilitado o freqüente uso da via subaracnóidea, através da síntese e da pesquisa experimental e clínica de novos fármacos. Apesar de a morfina ser o único medicamento reconhecido pelo FDA para aplicação subaracnóidea, outros fármacos têm sido administrado com segurança através desta via. Pesquisas em animais e em seres humanos demonstraram que medicamentos como o baclofen, a clonidina, os inibidores da acetilcolinesterase e a cetamina, dentre outros, são promissores para o tratamento da dor seja aguda ou crônica; contudo, novos e exaustivos estudos ainda são necessários.

Acredita-se que, futuramente, os medicamentos de uso subaracnóideo aplicados através de sistemas implantáveis sejam considerados como uma das primeiras alternativas para o controle dos sintomas álgicos, já que estão associados à menor incidência de efeitos indesejáveis e à maior comodidade para o paciente.

\section{Intrathecal Drugs for Chronic Pain Control}

Anita Perpétua Carvalho Rocha, M.D., Lino Lemonica TSA, M.D., Guilherme Antônio Moreira de Barros, M.D.

\section{INTRODUCTION}

Pain is a complex sensorial manifestation, often unrelated to tissue injury severity. According to the International Association for Study of Pain (IASP), it is defined as an uncomfortable emotional experience and sensation associated to actual or potential tissue damage. Pain is a frequent symptom in the daily practice and may be acute or chronic. The acute pain has a major physiological role being an early sign of potential threats. Conversely, chronic pain does not have a defined biological role and may be defined as pain persisting beyond a reasonable period after the healing of the underlying injury. It is in general pathologic, being associated to inability and physical, economic or emotional stress. It is a frequent complaint in patients with different diseases and the treatment is a challenge for health professionals who are in continuous search for new therapeutic strategies.

Systemic analgesics and conservative therapies are effective in controlling most patients' pain. In many cases, however, especially in neuropathic pain patients, more aggres- 
sive treatments are needed. Reversible methods modulating pain transmission at spinal level are proposed and include spinal cord electric stimulation and intrathecal administration of analgesics, by demand bolus or continuous infusion pump, or patient controlled infusion equipment.

Currently, morphine is the only drug approved by the United States Food and Drug Administration (FDA) for continuous intrathecal administration. However clinical and animal studies are being performed aiming at proposing new opioid alternatives. Opioids are associated to undesirable side-effects and a to very strong stigma among laymen or even physicians, facts which have contributed for the search of new adjuvant analgesic drugs. So, the administration of other classes of drugs has been proposed to control pain.

Several receptors and substances modulating pain transmission have been identified. There is a wide variety of agents acting specifically or not on receptors and it is possible that their isolated or combined administration may imply a better pain control with less undesirable effects.

Intrathecal administration of drugs is in general achieved by infusion pumps. However, this type of administration is associated to potential complications. It is believed that alternative mechanisms should be created for intrathecal administration of analgesics and this has motivated several experimental, laboratorial and clinical studies. It is estimated that in the short-term, cells and encapsulated substances will be implanted in this space to relieve chronic pain ${ }^{1}$.

\section{SPINAL ANALGESICS \\ Opioids (morphine, fentanyl and sufentanil)}

Opioids are often used to treat pain in patients with acute or chronic diseases. They are used in several situations and by different routes: oral, parenteral or intrathecal. Patients' clinical status and drug pharmacokinetics will define the preferential route.

Opioids multiplicity of actions is a result of their interaction with different receptors. Studies have shown the existence of several receptors, the most popular being MU $(\mu)$, KAPPA $(\kappa), \operatorname{SIGMA}(\zeta), \operatorname{DELTA}(\delta)$ and EPSILON $(\xi) . \mu$ receptors are divided in two sub-types: $\mu 1$, with high affinity to opioids, and $\mu 2$, with low affinity to opioids. Opioid activities are manifested according to the interaction and affinity to receptors and their intrinsic activity. $\mu 1$ receptors are related to spinal and supra-spinal analgesia, hypothermia and prolactin release. $\mu 2$ receptors are related to respiratory depression, bradycardia and decreased gut motility. Both receptors are related to euphoria, dependence and myosis. $\delta$ receptors are related to respiratory depression, addiction, arterial hypotension, hyperthermia and response to toxins. $\kappa$ receptors are related to intrathecal analgesia, sedation and myosis, while $\zeta$ receptors are related to dysphoria, hallucinations, mydriasis, tachycardia and arterial hypertension. $\xi$ receptors are associated to stress ${ }^{2,3}$. Opioids induce selective pain relief without affecting consciousness, provided they are administered in the adequate dose. Analgesia is a consequence of actions in different central (CNS) and peripheral nervous system levels. In the spinal cord, they inhibit noxious inflow transmission, probably by acting on pre-synaptic terminations, preventing the release of excitatory neurotransmitters, such as substance $P$. In the supra-medullary region, they act by stimulating descending analgesic systems which inhibit nociceptive medullary transmission. Such different action sites explain the differentiated dose-dependent response of some opioids, such as morphine ${ }^{4}$.

Opioid-induced analgesia is quantitatively and qualitatively differentiated, according to the ability to stimulate $\mu, \kappa, \delta$ and $\xi$ receptors. Drugs acting on $\mu$ receptors, such as morphine, have virtually ilimited analgesic effects and, in high doses, may relieve any type of pain. Drugs acting on $\kappa$ receptors have limited analgesic action, the so-called ceiling effect, which does not increase as a function of dose; so, they have a moderate level of selective activity and are able to antagonize opioids ${ }^{5}$.

Opioids are routinely used for intrathecal administration and, as compared to systemic administration, they are associated to a lower incidence of side-effects, lower dose requirements and longer duration because intrathecal administration allows for a better and direct access to the receptor.

Most opioids may be intrathecally administered, however, their physicochemical properties, molecular weight and liposolubility, their intrinsic affinity for opioid receptors and their pharmacokinetics will determine the efficacy of analgesia, the incidence and the severity of undesirable effects.

Opioids are selected based on their liposolubility. Liposoluble opioids are promptly spread through membranes and spinal cord, producing a fast onset of analgesia. Hydrosoluble opioids cross these tissues slower and have a later onset. However, the more liposoluble the opioid, the higher the possibility of being absorbed by vessels and fat, or nonspecific receptor sites. So, these agents have an action inversely proportional to they liposolubility. Hydrosoluble agents remain in the cerebral spinal fluid (CSF) for a longer period and slowly migrate to higher spinal cord levels. Analgesia may vary from 4 to 6 hours with sufentanil, reaching 24 hours with morphine.

Hydrosoluble drugs, such as morphine, have a well-established role for continuous infusion, but liposoluble opioids may also be administered in continuous infusion. Studies have been carried out with fentanyl and sufentanil, showing that such drugs may have a major role in treating localized pain syndromes when the catheter is close to the gelatinous substance in the nerve root corresponding to the region affected by pain ${ }^{6-10}$

Opioid doses for continuous intrathecal infusion are still not well established, but boluses have been used to control pain with a good response (Table I).

Intrathecal administration of opioids, although relatively recent, is in general associated to total pain control. In spite of the high effectiveness of such agents, some patients have unsatisfactory responses to treatment or develop drug tolerance and intolerance, which has led to the search of new adjuvant agents. 
Table I - Intrathecal Opioid Doses for Analgesia ${ }^{80}$

\begin{tabular}{lccc}
\hline Opioid & $\begin{array}{c}\text { Bolus dose } \\
(\mathrm{mg})\end{array}$ & $\begin{array}{c}\text { Onset } \\
(\mathrm{min})\end{array}$ & $\begin{array}{c}\text { Bolus Dose } \\
\text { Duration }(\mathrm{h})\end{array}$ \\
\hline Morphine & $0.1-0.3$ & 15 & $8-24$ \\
Meperidine & $10-30$ & - & $10-24$ \\
Sufentanil & $0.001-0.005$ & $4-10$ & $2-4$ \\
Fentanyl & $0.005-0.025$ & 5 & $3-6$ \\
\hline
\end{tabular}

\section{LOCAL ANESTHETICS \\ (lidocaine, bupivacaine and ropivacaine)}

Spinal local anesthetics administration has a long history and has been firstly reported by Bier in 1899. The concept of continuous infusion was introduced by Lemmon and, in 1948, Lofgren presented his thesis advocating the use of spinal lidocaine and introducing its use for surgical procedures ${ }^{11-13}$.

LAs such as lidocaine, bupivacaine and, more recently, ropivacaine, have a well-defined role in controlling pain by inactivating voltage-gated sodium channels. Their pharmacological action depends on physico-chemical characteristics, such as molecular weight, liposolubility, ionization level and protein affinity ${ }^{14}$. Liposolubility determines analgesic potency; pka determines blockade onset; and protein affinity determines analgesia duration. LAs combine with protein receptors located in the sodium channel of the nervous membrane. Higher affinity compounds are more strongly bound to receptor sites, remain in the channel for a longer period and have a longer conductive blockade ${ }^{15}$.

Differences between in vitro and in vivo results seem to be related to vasodilating properties or to tissue spreadability of different LAs. Lidocaine induces more vasodilation as compared to bupivacaine, thus implying more vascular absorption ${ }^{14}$. Conductive blockade onset depends on some factors, such as spreadability through non-nervous tissues and anesthetic concentration.

Major local anesthetics electrophysiological effect is observed during the action potential depolarizing phase. There is a decrease in speed and depolarization level, in a way that transmission excitation threshold is no longer reached and the nervous impulse is no longer propagated throughout the nerve.

Some authors believe that the effect on sodium flow is mediated via calcium-LA interaction. By increasing or decreasing ion calcium concentration around the nerve, it is possible to, respectively, antagonize or potentiate analgesic blockade, suggesting a competition between LA and membrane-bound calcium $^{16}$.

LAs may be used for regional block or systemic administration and are considered effective in treating nociceptive or neuropathic pain ${ }^{17}$. They are, however, related to undesirable effects such as tolerance, urinary retention, paresthesia, postural hypotension, bradypnea and dyspnea. These drugs may be administered alone or associated to opioids. Such combination allows for better analgesia with lower incidence of undesirable effects.

Revista Brasileira de Anestesiologia

Vol. 52, N 5, Setembro - Outubro, 2002
Usual spinal doses are differentiated according to the drug (Table II). However, variations in concentration and infusion rates are common, making difficult the use of local anesthetics in pre-programmed infusion pumps.

Table II - Intrathecal Local Anesthetic Doses for Analgesia

\begin{tabular}{lccc}
\hline Anesthetic Drug & $\begin{array}{c}\text { Bolus Dose } \\
(\mathrm{mg})\end{array}$ & Onset $(\mathrm{min})$ & $\begin{array}{c}\text { Bolus Dose } \\
\text { Duration }(\mathrm{h})\end{array}$ \\
\hline Lidocaine & $50-100$ & $10-15$ & $30-50$ \\
Bupivacaine & $7-15$ & $<1 \mathrm{~min}$ & $3-4$ \\
Ropivacaine ${ }^{*}$ & - & - & - \\
\hline
\end{tabular}

* Not described dose in humans

\section{$\alpha_{2}$-ADRENERGIC AGONISTS \\ (cocaine and clonidine)}

$\alpha_{2}$-adrenergic analgesic mechanisms have been investigated for more than 100 years. Cocaine, the first intrathecal anesthetic drug, induces analgesia primarily by acting as local anesthetics, but also by inhibiting norepinephrine reuptake. Cocaine-induced spinal analgesia is partly due to $\alpha_{2}$ receptors noradrenergic stimulation. This finding has motivated the use of $\alpha_{2}$-adrenergic agonists for analgesia. However, it was only in 1984 that clonidine was successfully administered, when Tamsen et al. ${ }^{18}$, after neurotoxicity tests in animals, injected this drug in the epidural space of two patients with chronic pain. This has paved the road for further studies which have shown the safety of intrathecal clonidine for treating painful syndromes.

Currently, intrathecal clonidine is used in association with other drugs to treat difficult to control pain. Intrathecal clonidine is effective in refractory cancer pain, complex regional pain syndrome (CRPS) and postoperative pain, in prolonging local anesthetic effects and in potentiating the effectiveness of other neuraxial agents.

Clonidine's analgesia is a function of its action on peripheral, spinal and/or cerebral $\alpha_{2}$-agonist receptors. It may be used by different routes being more potent after neuraxial administration as compared to systemic administration. Evaluating analgesia with equal clonidine doses administered by both routes, it has been observed that intrathecal injection in low doses $(150 \mu \mathrm{g})$ after Cesarean section and minor orthopedic surgeries induces analgesia for 4 to 6 hours, while intramuscular injections of the same doses induce analgesia similar to placebo ${ }^{19,20}$. In comparing epidural and intravenous clonidine in high doses, it was observed that epidural clonidine induces better analgesia and is associated to less opioid requirements ${ }^{21,22}$. Some studies have shown that intrathecal is more potent that epidural clonidine, especially to treat acute pain. Eisenach et al. ${ }^{23}$, have shown that intrathecal clonidine is ten times more potent than epidural for treating postoperative pain, and twice as effective to control neuropathic pain. Intrathecal clonidine induces analgesia by increasing spinal norepinephrine release, which has an important role in descending pain inhibitory system ${ }^{24}$. Although acting by nora- 
drenergic stimulation, recent studies have shown that noradrenergic drugs analgesia is partly a consequence of the activation of spinal cholinergic neurons. Anatomic studies have shown high density of muscarinic and $\alpha_{2}$-adrenergic receptors in superficial dorsal column areas ${ }^{25}$ and functional animal studies have indicated the presence of antinociceptive effects of those receptors after intrathecal administration ${ }^{26}$. This interaction is suggested by the antinociceptive action potentiation of intrathecal $\alpha_{2}$-adrenergic agonists when associated to cholinesterase inhibitors, such as neostigmine ${ }^{27}$, and by the inhibition of this effect by intrathecal injection of muscarinic antagonists, such as atropine ${ }^{28}$. In addition, the administration of $\alpha_{2}$-adrenergic agonists in doses able to induce antinociception in sheep, increases the concentration of acetylcholine in the CSF, effect which is potentiated by physostigmine and blocked by $\alpha_{2}$-adrenergic antagonists, such as idazoxan ${ }^{29}$. This suggests that clonidine's analgesic effect is induced by different mechanisms, that is, by blocking $\mathrm{C}$ and $\mathrm{A} \delta$ fibers nervous conduction ${ }^{30}$, by increasing medullary acetylcholine concentration and by increasing central nervous system norepinephrine levels ${ }^{31}$, thus contributing for a better opioid and local anesthetics analgesia.

Studies evaluating intrathecal clonidine have shown that 15 to $45 \mu \mathrm{g}$ are enough to help analgesia in orthopedic procedures $^{32}$, and that 2 to $30 \mu \mathrm{g} \cdot \mathrm{h}^{-1}$ continuous infusion are effective to treat chronic pain associated to regional complex pain syndrome ${ }^{33}$. However, care must be taken with the fact that the concentration of commercially available clonidine preparations is $150 \mu \mathrm{g} \cdot \mathrm{ml}^{-1}$, implying the need for $2 \mathrm{ml}^{\text {d day }}{ }^{-1}$ for an effective analgesia. This infusion rate makes difficult the use of such agent in the clinical practice because pre-programmed infusion pumps in general release 0.15 to $0.5 \mathrm{ml} \mathrm{a} \mathrm{day}{ }^{34}$. Intrathecal clonidine is a promising adjuvant in pain treatment, but its clinical use has been limited by undesirable effects, especially hemodynamic changes and sedation. Dexmedatomidine, a new selective $\alpha_{2}$-agonist, is being studied and seems to be related to promising clinical results with less adverse effects when intrathecally injected.

\section{EXCITATORY AMINOACIDS ANTAGONIST (ketamine)}

Excitatory Aminoacids (EAA) are key to nociceptive transmission. Glutamate and aspartate are the major excitatory neurotransmitters of somatosensory transmission pathways and are present in peripheral nerves, dorsal root ganglia and axons and spinal cord dorsal horn cells, where they bind to specific receptors.

There are several receptors in the spinal cord dorsal horn neurons (SCDH), among them N-methyl-D-Aspartate (NMDA) and non-NMDA receptors. There are two non-NMDA receptors sub-types: alpha-amino-3-hydroxi-5-methylsoxazole-4 propionic (AMPA) acid and cainate, which are activated soon after EAA release and are involved in the time-space location mechanism and in pain quantification. When activated, NMDA receptors contribute for SCDH neurons sensitization, influencing chronic pain generation and nociception modulation.

Several sensitive SCDH neurons are activated by mechanical, thermal and nociceptive stimulations. These stimulations increase SCDH neurons excitability and lead to the activation of previously inactive NMDA synapses, with consequent secondary hyperalgesia and allodynia. Persistent painful stimulations sensitize SCDH neurons by receptors phosphorilation ${ }^{35}$.

In general, the removal of the nociceptive agent controls hyperalgesia and allodynia in a matter of hours or days. However, prolonged nociceptive stimulation may result in persistent pain, even without the triggering agent, as a consequence of SCDH neurons sensitization mechanisms structuring. This would be one mechanism responsible for chronic pain. It is admitted that $\mathrm{SCDH}$ receptor antagonists may block pain sensitization and chronification ${ }^{36}$.

NMDA receptors are a sub-type of glutamate receptors, and are classified according to pharmacological criteria by their selective agonist N-methyl-D-aspartate. They have ionotropic characteristics and incorporate in their structure a binding site of the transmitter to a specific cationic channel, made up of several protein sub-types. The activation of NMDA receptors is voltage-gated and the action of neuropeptides leads to their cell membrane adepolarization, releasing ionic channel magnesium and increasing sensitivity to glutamate and calcium inflow to the cell. This change in the membrane triggers a series of events which change neuronal response to subsequent stimulations and peaks with the so-called wind-up phenomenon, that is, gradual increase in nervous response, both in magnitude and duration, to repeated $\mathrm{C}$ fiber stimulations. Physiological concentrations of magnesium block the receptor and prevent EAA binding to its specific site. However, the administration of non-NMDA receptor antagonists, even in high doses, does not affect pain transmission.

Several studies have focused on the use of NMDA receptor antagonists to control and decrease the development of wind-ups. One way would be the use of high opioid doses able to inhibit wind-ups. Chapman et al. ${ }^{37}$ have shown that opioids and NMDA antagonists work synergistically to inhibit nociception. According to Ma et al. ${ }^{38}$, intrathecal non-NMDA antagonists prevent and decrease tactile pain in rats. Similarly, Yamamoto et al. ${ }^{39}$ have concluded that NMDA receptors have a role in the development of hyperesthesia subsequent to nervous injury. They have observed that low intrathecal NMDA antagonist doses temporarily abolish such hyperesthesia.

The first step for the use of intrathecal NMDA antagonists in humans was given by Kristensen et al. ${ }^{39}$, who studied the effects of intrathecal phencyclidine (PCP) in rats, aiming at determining its potential neurotoxicity, have found no difference between PCP and saline. This study has also described a case of intrathecal PCP in a patient with untreatable lower limb neurogenic pain, associated to secondary hyperalgesia, which was relieved with PCP. Intrathecal ketamine has been used in humans. Several studies were carried out in the 
past, but were limited by the drug's potential neurotoxicity. Recent animal studies have failed in showing spinal cord abnormalities after ketamine with preservative. Yang et al. ${ }^{40}$ have shown that intrathecal ketamine increases opioid analgesic effects in cancer patients. Limitations to its intrathecal use include its well-described psychotropic effects, vomiting, numbness, arterial hypertension, tachycardia and, less frequently, cardiovascular depression.

NMDA antagonists have shown to be a good therapeutic alternative to treat cancer pain and chronic neuropathic pain. Most common doses vary according to the administration route: $1 \mathrm{mg} \cdot \mathrm{kg}^{-1}$ intravenous or epidural bolus, followed by less than $20 \mu \mathrm{g} . \mathrm{kg} \cdot \mathrm{min}^{-1}{ }^{41}$ continuous infusion; intrathecal doses have not yet been established. Further studies are needed to establish the optimal dose since, in spite of well-documented analgesic effects, NMDAantagonists are associated to major undesirable effects.

\section{INHIBITORY AMINOACIDS}

(benzodiazepinics and baclofen)

Gamma-aminobutyric acid (GABA) and glycine are inhibitory aminoacids (IAA) acting as neurotransmitters in the central nervous system ${ }^{42,43}$. GABA receptors are present in dorsal and lateral funicles, in the Lissauer's tract and in Rexed laminae I, II and III. There are three types of GABA receptors: GABA-A, GABA-B and GABA-C ${ }^{44}$. GABA-A receptor is part of an ionic complex with chlorine ${ }^{45}$, the agonist of which is muscimol and the selective antagonist is gabazine. Barbiturates and alcohol modulate this receptor's activity by direct facilitation of chlorine inflow ${ }^{46}$. Benzodiazepinics bind to a specific site in the GABA-A receptor complex helping the GABA receptor-antagonist binding and increasing ion channel opening time ${ }^{47}$. GABA-B receptor is a binding complex with protein- $G$ and, when activated, increases potassium outflow $^{44}$. Baclofen is a selective GABA-B agonist and faclofen is a selective antagonist. More recently, there have been speculations about a GABA-C receptor, which is also directly associated to potassium channels. Cis-4-aminochrotonic acid is a selective GABA-C receptor agonist, so far with no selective antagonist.

Both GABA-A and GABA-B agonists have analgesic properties after intrathecal administration in chronic pain models. Serrao et al. ${ }^{48}$ have shown that intrathecal midazolam, a GABA-Aagonist, was effective in treating lumbar mechanical pain. Borg et al. ${ }^{49}$ had excellent results with intrathecal midazolam and clonidine in chronic pain patients. Animal studies carried out in 1980 have attributed anti-nociceptive properties to intrathecal midazolam. Finally, in 1986, midazolam was administered in humans and it was shown that analgesia was due to the action on GABA-A receptors and $\mu$ and $\kappa$ receptors present in pain transmission pathways ${ }^{50}$. Studies have shown that refractory pain syndrome patients, when submitted to intrathecal midazolam, experience unique dose and concentration-dependent analgesia. Single doses in patients without previous contact with this treatment promote analgesia within 4 to 5 minutes with 5 to 8 days relief. Patients with in- trathecal systems implanted for drug release may ask for $0.83 \mu \mathrm{g}$ boluses every 6,8 or 12 hours which, as a function of poor cephalad spread, are associated to few side-effects. Taira et al. ${ }^{51}$ have observed intrathecal GABA agonist analgesia with intrathecal baclofen, a GABA-B agonist muscle relaxant with central action, in patients with central pain after a stroke. Herman et al. ${ }^{52}$ have shown intrathecal baclofen analgesia in patients with spinal cord injury related to spasticity and dysesthesic pain; for such reason, it has been often indicated to control spasticity-related pain. Albright et al. ${ }^{53}$ and Penn et al. ${ }^{54}$ have shown muscle tone and spasm decrease in $97 \%$ of patients. There were other benefits as a function of decreased spasticity, such as decreased pain, and improved sleep, intestinal and bladder function, which implied better quality of life. Pre-programmed intrathecal pumps have been used to release baclofen in the treatment of severe spasticity. Recent studies ${ }^{54.55}$ have shown that intrathecal baclofen is safe and effective for those cases and is not associated to histopathological changes or physiological neurotoxicity. A study by Satoh et al. ${ }^{56}$ has shown that intrathecal baclofen is active in controlling neuropathic pain in 25 to 75 $\mu \mathrm{g}$ boluses followed by 3 to $8 \mu \mathrm{g} \cdot \mathrm{h}^{-1}$ continuous infusion. This drug alone, however, is not sufficient for total symptoms control and have to be combined with other oral drugs, such as anticonvulsivants, antidepressants, opioids and anti-inflammatory drugs ${ }^{80}$.

\section{ACETYLCHOLINE AND \\ ACETYL-CHOLINESTERASE INHIBITORS}

(neostigmine)

Acetylcholine is a potent analgesic from the monoamine family. There are many central nervous system cholinergic receptors, especially in the raphe nuclei, ambiguous nucleus, motor nucleus of vagus and neurons located in the dorsal column. Nicotinic and muscarinic cholinergic receptors are present in the spine and the administration of their agonists has induced analgesia in several animal studies. Papers have shown that this effect is additive to morphine ${ }^{57,58}$ and is a consequence of cholinergic agonists action in different sites. Intrathecal acetyl-cholinesterase inhibitors, such as neostigmine, inhibit the breakdown of spinal cord endogenous neurotransmitters, inducing analgesia. Acetylcholine release in the spinal cord is stimulated by pain, by systemic opioids and by intrathecal $\alpha_{2}$-adrenergic agonists ${ }^{59}$. In addition, acetylcholine's analgesic effect seems to involve nitric oxide production stimulation since increased nitric oxide levels in the spinal cord are seen after intrathecal acetylcholine ${ }^{59}$. In preliminary studies carried out in volunteers, 10 to $50 \mu \mathrm{g}$ intrathecal neostigmine has promoted analgesia ${ }^{60}$. Neostigmine doses above $100 \mu \mathrm{g}$ cause nausea and lower limb weakness, but do not increase the incidence of sedation, pruritus, respiratory depression or hemodynamic changes ${ }^{61}$. In fact, intrathecal neostigmine increases the activity of sympathetic neurons and opposes local anesthetics and $\alpha_{2}$-adrenergic agonists sympathicolytic effects ${ }^{62}$, preventing hypotension. Gordh et al. ${ }^{63}$ have observed that intrathe- 
cal clonidine analgesia is synergistically improved by neostigmine. These authors have stated that intrathecal $\alpha_{2}$-adrenergic agonists induce analgesia partly by cholinergic spinal neurons activation. In addition, intrathecal muscarinic agonists or neostigmine increase blood pressure and heart rate by acting on pre-ganglial sympathetic neurons. The co-administration of neostigmine and clonidine controls clonidine-induced hypotension in sheep, meaning that this effect might be also true in humans, implying benefits for the patient ${ }^{64}$. Temporal regulation, however, might become a problem since neostigmine's hypotensive effects seem to be late as compared to the faster onset of clonidine and local anesthetics hypotensive effects ${ }^{60}$.

Cholinesterase inhibitors have shown to be promising adjuvant drugs for treating acute and chronic pain, but the high incidence of side-effects and the uncertainty about the effective dose are obstacles for their clinical use. The identification of elements to fight these adverse effects is desirable and could imply benefits for the daily practice.

\section{CALCIUM CHANNEL BLOCKERS (diltiazem, nimodipine and verapamil)}

Calcium inflow and outflow in spinal cord cells are important for neural function. Excitatory neurotransmitters release is coupled to the activation of voltage-gated calcium channels activation. So, calcium is essential to regulate neuronal excitability and neurotransmitters release with further synaptic depolarization. Four calcium channels were identified in dorsal root ganglia and neurons: L, N, T and P. Of those, only channel $\mathrm{P}$ is involved in neural excitability regulation. Intrathecal conapeptides, or calcium channel type T antagonists, relieve neuropathic pain in rats ${ }^{65}$, attenuating both formalin test phases and preventing capsaicin-induced hyperalgesia. However, marked motor abnormalities have persisted for two to three days after conatoxin administration.

Calcium channel antagonists diltiazem and nimodipine have analgesic properties. Verapamil in combination with well-established analgesics, such as morphine, has shown to be a major promise for the future ${ }^{66}$. Opioids inhibit nociception by blocking voltage-gated calcium channels and activating proteins $\mathrm{G}$. So, it is possible that calcium channels conductance inhibition could promote analgesia or, at least, improve opioids analgesia.

\section{Adenosine}

Adenosine triphosphate (ATP) is a nucleotide present in all human body cells and is critical for cell metabolism. ExtracelIular ATP and its metabolite adenosine, have marked effects in several biological processes, such as liver glycogen metabolism, muscle contraction, heart function, platelet function and neurotransmission. The effect of adenosine is mediated by two superficial cell receptor sub-types: receptor $A 1$ and receptor A2. Sub-type A1 is involved in spinal pain transmission modulation and acts by inhibiting adenylcyclase activity resulting in decreased pre-synaptic calcium inflow and/or inhibition of substance P immunoreactivity. Intrathecal adenosine has been used with some success to treat chronic neuropathic pain. Its use, however, is associated to a higher incidence of back pain ${ }^{67}$, with an additional disadvantage which is the need for continuous infusion since it has a short half-life. Anyway, the role of adenosine in controlling difficult to manage chronic pain is very complex. Further studies are needed for this substance to be safely used in the clinical practice.

\section{Serotonin}

Serotonin $(5 \mathrm{HT})$ is a monoamine involved in the stimulation of descending pain control pathways. It is present in the spinal cord dorsal horn, primarily in Rexed laminae I and II and in the ventral portion of the spinal cord. Studies have shown that the stimulation of analgesia-related areas is associated to increased serotonin levels ${ }^{68}$

Descending pain inhibitory system consists of several central anatomic connections, starting by the periaqueductal gray matter which, in turn, receives afferences from several diencephalic nuclei, such as parafascicular nucleus of thalamus, mamillary dorsal nucleus, zona incerta, dorsomedial and ventromedial hypothalamic nuclei, arcuate nucleus and brainstem. Periaqueductal gray matter sends projections to the paragigantocellular nucleus and magnum raphe nucleus (MRN). MRN sends serotoninergic fibers which project through the dorsolateral funicle to the spinal cord dorsal horn in laminae I, II and IV, where it selectively inhibits nociceptive neurons, including interneurons and ascending tract neurons. Electric MRN stimulation increases serotonin release in the spinal cord dorsal horn, but this effect is blocked by pre-treating patients with p-chlorophenylalanine (pCPA), which is a serotoninergic antagonist. Similarly, noxious stimulation increases the production of 5-hydroxyindolacetic acid, which is a serotonin metabolite ${ }^{69,70}$.

Several well-established drugs induce analgesia by acting on the serotoninigergic system. In spite of evidences, practical results have been contradictory. Mjellem et al. ${ }^{71}$ have shown that the activation of 5 -HT receptors induces analgesia. However, Fozard in 1984 and Richardson et al. ${ }^{72,73}$ in 1985 have observed a noxious effect of serotonin when peripherally administered, but an antinociceptive effect when administered in the neuraxis. Further studies are needed to establish the real role of serotonin in pain control.

\section{TRICYCLIC ANTIDEPRESSANTS} (amitriptyline)

Tricyclic antidepressants (TAD) are well-established drugs to treat chronic pain. Their role in modulating pain is well documented in terms of their action on serotonin and norepinephrine reuptake, which are substances involved in pain transmission inhibition. In vitro studies have shown the action of TADs in NMDA receptors ${ }^{74,75}$, which would better explain the control of chronic pain symptoms, such as allodynia and hyperalgesia. 
Animal studies have shown that intrathecal TADs revert hyperalgesia and that the mechanism involved in controlling pain is similar to that seen with NMDA receptor antagonists. Eisenach et al. ${ }^{76}$ have shown NMDA-induced hyperalgesia reversion after intrathecal amitriptyline. They have observed that the mechanism involved is not related to monoamines reuptake inhibition, since fentolamine does not revert TAD effects on neuropathic pain and, as a consequence, on neuropathic pain-related hyperalgesia and allodynia. According to the same authors, intrathecal amitriptyline has a synergistic effect with intravenous morphine. Currently, the use of intrathecal TADs has been impaired by the lack of preservative-free preparations and by the observation of undesirable effects in rats, such as muscle weakness. Good results obtained in animal studies reinforce the importance of identifying substances to be used by this route.

\section{PROSTAGLANDIN SYNTHESIS INHIBITORS (ketorolac)}

Prostaglandins and leucotriens are synthesized from the arachidonic acid through the action of cycloxygenase and lipoxygenase, respectively. Prostaglandins and leucotriens are important for the sensitization of peripheral primary afferent fibers and for the induction of primary hyperalgesia. However, prostaglandins have also a role in central pain transmission in the dorsal column. Calcium inflow to glial neuron and cells after nociceptors stimulation activates phopholipase A2 and breaksdown arachidonic acid. Arachidonic acid is brokendown by cycloxygenase type 2 at the central level and by cycloxygenase type 1 at the peripheral level, giving origin to prostaglandin. Prostaglandin effects in pain transmission are mediated by the neuronal increase in calcium and cyclic AMP levels, maybe increasing neurotransmitters and neuromodulators excitability and release. It is believed that such reactions are stimulated by NMDA receptors.

Intrathecal cycloxygenase inhibitors have been proposed to control chronic pain. Malmberg et al. ${ }^{77}$ have shown that intrathecal ketorolac inhibits the development of hyperalgesia. This non-opioid, however, has a limited effect in controlling acute pain. Opioids alone induce dose-dependent suppression of both phases: acute and chronic. When associated to morphine, ketorolac produces a synergistic antinociceptive effect. Kerotolac has also synergism with $\alpha_{2}$-adrenergic agonists. Further studies are needed to rule out possible neurotoxicity and undesirable effects before introducing this intrathecal drug in the clinical practice.

\section{POTENTIAL DRUGS FOR FUTURE USE}

Nitric oxide synthesis inhibitors have shown to be promising to control chronic pain. It is known that nitric oxide has a role in sensorial transmission and that its synthesis is stimulated by increased intracellular calcium after NMDA receptors opening. Studies have shown that nitric oxide is involved in the development of wind-ups and several types of hyperalgesia ${ }^{78}$. Intrathecal arginine analogs, which are nitric oxide synthesis inhibitors, produce dose-dependent decrease of nervous injury-induced hyperalgesia ${ }^{79}$.

Cholecystokinin (CCK), an important GI tract regulator and central nervous system neurotransmitter, has a role in pain transmission. It is believed that specific agonists of CCK-B receptors would block induction, but not maintenance, of central sensitization.

Substance $P$ belongs to the tachykinin family and is found both centrally, in gelatinous substance and spinal cord dorsal horn neurons, and peripherally. It is bound to NK1 receptors and is associated to nociceptive information transmission and modulation. It is believed that spinal substance P antagonists could have antinociceptive properties. Intrathecal capsaicin implies marked substance $\mathrm{P}$ decrease in the dorsal root. It is however associated to myelinized afferents degeneration.

\section{CONCLUSIONS}

The control of acute or chronic pain has experienced huge progresses in the last decades. Through synthesis and experimental and clinical research, Medicine has allowed for the frequent use of the intrathecal route. Although morphine is the only drug approved by the FDA for intrathecal use, other drugs have been safely administered by this route. Animal and human studies have shown that drugs such as baclofen, clonidine, acetyl-cholinesterase inhibitors and ketamine, among others, are promising to treat both acute and chronic pain; however, new exhaustive studies are still needed. It is believed that in the future, intrathecal drugs administered through implanted systems will be considered one of the first alternatives to control pain, since they are associated to low incidence of side-effects and additional comfort for patients.

\section{REFERÊNCIAS - REFERENCES}

01. Dougherty $P$, Staats $P$ - Intrathecal drug therapy for chronic pain: from basic science to clinical practice. Anesthesiology 1999;91:1891-2026.

02. Mark CR - Princípios e Prática de Anestesiologia. $1^{\text {a }}$ Ed, Editora Afiliada, 1996;1060-1073.

03. José Jr OO - Opiáceos, O Estado D’arte. $1^{\text {a }}$ Ed, Lemar, 2001;17-18

04. Alan NS - Clínica Cirúrgica da América do Norte. Controle da Dor no Período Perioperatório. $1^{\mathrm{a}} \mathrm{Ed}$, Editora Harcourt, 1999;79: 233-250.

05. Renê C - Dor Mecanismos e Tratamento. 1ª Ed, Porto Alegre. Editora Artmed 1999;103-112.

06. Shertter Ag, Hadley MN, Wilkinson E - Administration of intraspinal morphine sulfate for the treatment of intractable cancer pain. Neurosurgery, 1986;18:740-747.

07. Auld AW, Maki-Jokela A, Murdoh DM - Intraspinal narcotic analgesia in the treatment of chronic pain. Spine, 1985;10:777-781.

08. Krames ES, Gershow J, Glassberg A - Continuos infusion of spinally administered narcotics for the relief of pain due to malignant disorders. Cancer, 1985;56: 696-702.

09. Houweling PI, Ionescu TI, Braams R - Hormonal and pharmacokinetics after intradural (spinal) morphine and general anaesthesia for abdominal aortic surgery. Clinical Drug Investigation, 1999;17:1173-2563. 
10. Young ER, Mackenzie TA - The pharmacology of local anesthetics - A review of the literature. J. Can Dent Assoc, 1992;58: 34-42.

11. Maves TJ, Gebhart GF - Antinociceptive synergy between intrathecal morphine and lidocaine during visceral and somatic nociception in the rat. Anesthesiology, 1992;76:91-99.

12. Chaplan SR, Bach FW, Shafer SL - Prolonged alleviation of tactile allodynia by intravenous lidocaine in neuropathic rats. Anesthesiology, 1995;83:775-785.

13. Lou L, Wiesenfeld-Hallin Z - Effects of intrathecal local anesthetics on spinal excitability and on the development of autonomy. Pain, 1995;63:173-179.

14. Barash - Refresher Course in Anesthesiology. JB Lippincott Company, 1993;21:241-254.

15. Covino BG - General considerations, toxicity and complications of local anesthesia in nimmo. Blackwell Scientific Publications 1990;11:1033-1034.

16. Stoetting RK - Local Anesthetic. $2^{\text {nd }}$ Ed, London. Lippincott Company 1987;148-168.

17. Backonja MM - Adjuvant analgesic in pain management: iii local anesthetics as adjuvant analgesics. J. Pain Symptom Manage, 1994;9:491-499.

18. Tamsen A, Gordh T - Epidural clonidine produces analgesia. Lancet, 1984;2:231-232.

19. Bonnet F, Boico O, Rostaing S et al - Clonidine-induced analgesia analgesia in postoperative patients: epidural versus intramuscular administration. Anesthesiology, 1990;72:423-427.

20. Filos KS, Goudas LC, Patroni O et al - Intrathecal clonidine as a sole analgesic for pain relief after cesarean section. Anesthesiology, 1992;77:267-274.

21. De Kock M, Crochet B, Morimont C et al - Intravenous or epidural clonidine for intra and postoperative analgesia. Anesthesiology, 1993;79:525-531.

22. James CE, Marc DK, Walter K - Alpha ${ }_{2}$-adrenergic agonist for regional anesthesia. Anesthesiology, 1996;85:655-674.

23. Eisenach JC, Hood DD, Curry R - Relative potency of epidural to intrathecal clonidine differs between acute thermal pain and capsaicin-induced allodynia. Pain, 2000;84:57-64

24. Liu N - Partial reversal of the effects of extradural clonidine by oral yohimbine in postoperative patients. Br J Anaesth, 1993;70: 515-518.

25. Gordh Jr T, Jansson I, Hartoig P et al - Interaction between noradrenergic and cholinergic mechanisms involved in spinal nociceptive processing. Acta Anaesthesiol Scand, 1989;33: 39-47.

26. Hood DD, Eisenach JC, Tuttle R - The analgesic interaction between intrathecal neostigmina and epidural clonidine in humans. Anesthesiology, 1985;5:2359-2364.

27. Hood DD, Mallak KA, Eisenach JC et al - Interaction between intrathecal neostigmina and epidural clonidine in humans volunteers. Anesthesiology, 1996;85:315-325

28. Klimscha W, Tong C, Tommasi E et al - Intrathecal clonidine and dexmedetomidine stimulate acetylcholine release from spinal cord dorsal horn in sheep: an in vivo microdialysis study. Anesthesiology, 1995;83:A793.

29. Detweiler DJ, Eisenach JC, Tong C et al - A cholinergic interaction in alpha 2 adrenoceptor-mediated antinociception in sheep J Pharmacol Exp Ther, 1993;265:536-542.

30. Chiari A, Eisenach JC - Spinal anaesthesia: mechanisms, agents, methods, and safety. Reg Anesth Pain Med, 1998;23: 357-362.

31. Dahlstrom A, Fuxe K - Evidence for the existence of monoamine neurons in the central nervous system: II. Experimentalmentally induced changes in the intra-neural amine levels of bulbospinalneuron systems. Acta Physiol Scand, 1965;64:1-36.
32. Dekock M, Gautier PE, Lavand'hommem P - Intrathecal ropivacaine and clonidine for ambulatory knee arthroscopy: a dose response study. Anesthesiology, 1999;90:710-717.

33. Rauck RL, Eisenach JC, Jackson K et al - Epidural clonidine treatment for refractory reflex sympathetic dystrophy. Anesthesiology, 1996;94:873-881.

34. Staats PS, Mitchell VD - Progress in anesthesiology: Future directions for intrathecal therapies. Interv Pain Manag, 2000; $1-27$.

35. Melzack R, Wall PD - Textbook of Pain. $3^{\text {rd }}$ Ed, London. Churchill Livingstone, 1994;1025-1033.

36. Cotman CW, Monaghan DT - Excitatory amino acid neurotransmission: NMDA receptors and Hebb-type synaptic plasticity. Ann Rev Neurosci, 1988;11:61-80.

37. Champman V, Dickenson AH - The combination of NMDA antagonism and morphine produces profound antinociception in the rat dorsal horn. Brain Res, 1992;573:321-323.

38. Ma QP, Woolf C - Noxious stimuli induce an N-methyl-Daspartate receptor dependent hypersensitivity of the flexion withdrawal reflex to touch: implications for the treatment of mechanical allodynia. Pain, 1995;61:383-390.

39. Yamamoto T, Yaksh TL - Spinal pharmacology of thermal hyperesthesia induced by constriction injury of sciatic nerve. Excitatory amino acid antagonists. Pain, 1992;49:121-128.

40. Yang CY, Wong CS - Intrathecal ketamine reduces morphine requirements in patients with terminal cancer pain. Can J Anaesth, 1996;43:379-383.

41. Raeder JC, Stenseth LB - Ketamine: a new lock at an old drug. Current Opinion in Anaesthesiology, 2000;13:463-468.

42. Aprison MH, Shank RP, Davidoff RA - A comparison of the concentration of glycine, a transmitter suspect, in different areas of the brain and spinal cord in seven different vertebrates. Comp Biochem Physiol, 1969;28:1345-1355.

43. Rizzoli AA - Distribution of glutamic acid, aspartic acid, gamma-aminobutyric acid and glycine in six areas os cat spinal cord before and after transection. Brain Res, 1968;11:11-18.

44. Bowery N - GABAb receptors and their significance in mammalian pharmacology. Trens Pharmacol Sci, 1989;10:401-406.

45. Johnston GAR - GABAa receptor pharmacology. Pharmacol Ther, 1996;69:173-178.

46. Rabow LE, Russek SJ, Farb DH - From ion currents to genomic analysis: recent advances in GABAa receptor research. Synapse, 1995;21:189-274.

47. Monaghan DT, Olverman HJ, Nguyen L et al - Two classes of $\mathrm{N}$-methyl-D-aspartate recognition sites: differential distribution and differential regulation by glycine. Proc Natl Acad sci USA, 1988;85:9836-9840.

48. Serrao JM, Marks RL, Morley SJ et al - Intrathecal midazolam for the treatment os cronic mechanical back pain; a controlled comparison with epidural steroid in a pilot study. Pain, 1992;48:5-12.

49. Borg PA, Krijnen HJ - Long-term intrathecal administration of midazolam and clonidine. Clin J Pain, 1996;12:63-68.

50. Valentine JM, Lyons G, Bellamy MC - The effect of intrathecal midazolam on post-operative pain. European J Anesth, 1996; 13:589-593.

51. Taira $\mathrm{T}$, Tanikama $\mathrm{H}$, Iseki $\mathrm{H}$ et al - Spinal intrathecal baclofen suppresses central pain after a stroke. J Neural Neurosurg Psychiatry, 1994;57:381-382.

52. Herman RM, D'luzansky SC, Ippolito R - Intrathecal baclofen suppresses central pain in patients with spinal lesions. Clin J Pain, 1992;8:338-345.

53. Albright AL, Ceervi A, Singletary J - Intrathecal baclofen for epasticity in cerebral palsy. JAMA, 1991;265:1418-1422.

54. Penn RD - Intrathecal baclofen for spasticity of spinal origin: seven years of experience. J Neurosurg, 1992;6:115-118.

Revista Brasileira de Anestesiologia Vol. 52, N 5, Setembro - Outubro, 2002 
55. Parke B, Penn RD, Savoy SM et al - Functional outcome after delivery of intrathecal baclofen. Arch Phys Med Rehabil, 1989;70: 30-32.

56. Satoh O, Omote $\mathrm{K}$ - Roles of monoaminergic, glycinergic and GABAergic inhibitory systems in the spinal cord in rats with peripheral mononeuropathy. Brain Res, 1996;728:27-36.

57. Eisenach JC, Hood DD, Tuttle R - Phase 1 safety assessment of intrathecal neostigmina metyl sulfate in humans. Anesthesiology, 1995;82:331-343.

58. Abram SE, Winnie RP - Intratecal acetyl cholinesterase inhibitors produce analgesia that is synergistic with morphine and clonidine in rats. Anesth Analg, 1995;81:501-507.

59. Chiari A, Eisenach JC - Spinal anaesthesia: Mechanisms, agents, methods, and safety. Reg Anesth Pain Med, 1998;23: 357-362.

60. Liu SS, Hodgson PS, Moore JM et al - Dose-response effects of spinal neostigmina added to bupivacaine spinal anesthesia in volunteers. Anesthesiology, 1999;90:710-717.

61. Eisenach JC, Hood DD, Curry R - Phase I human safety assessment of intrathecal neostigmina containing methyl- and propylparabens. Anesth Analg, 1997;85:842-846.

62. Pan HL, Song HK, Eisenach JC - Effects of intrathecal neostigmina, bupivacaine, and their combination on sympathetic nerve activity in rats. Anesthesiology, 1998;83:842-846.

63. Gordh Jr T, Jansson I, Hartvig P et al - A colinergic interaction in alpha2 adrenoceptor-mediated antinociception. Anesthesiology, 1995;83:793-795.

64. Lauretti GR, Reis MP - Subarachnoid neostigmina does not affect blood pressure or heart rate during bupivacaine spinal anesthesia. Reg Anesth, 1996;21:586-591.

65. Malmberg AB, Yaksh TL - Effect of continous intrathecal infusion of 2-conapeptides, $\mathrm{N}$-type calcium-channel blockers, on behavior and antinociception in the formalin and hot-plate test in rats. Pain, 1995;60:83-90.

66. Omote K, Sonoda $\mathrm{H}$ et al - Potentiation of antinociceptive effects of morphine by calcium-channel blockers at teh level of the spinal cord. Anesthesiology, 1993;79:746-752.

67. Karlsten R, Gordh T, Post C - Local antinociceptive and hyperalgesic effects in the formalin test after periferical administration of adenosine analogues in mice. Pharmacol Toxicol, 1992;70:434-438.

68. Basbaum AL - Descending control of pain transmission: possible serotonergic-enkephalinergic interactions. Advances in experimental medicine and biology, 1981;133:177-189.

69. Basbaum Al, Fields HL - Endogenous pain control mechanisms: review and hypothesis. Ann Neurol, 1978;4:451-454.

70. Stamford JA - Descending control of pain. Br J Anaesth, 1995; 75:217-227.

71. Mjellem N, Lund A, Hole K - Different functions of spinal 5-HT 1 A and $5-\mathrm{HT} 2$ receptor subtypes in modulating behavior induced by excitatory amino acid receptor agonists in mice. Brain $\mathrm{Re}-$ search, 1993;626:78-82.

72. Fozard JR - The enigma variations. Trends Pharmacol Sci, 1987;8:501-506.

73. Richardson BP, Engel G, Danatsch et al - Identification os serotonin M-receptor subtypes and their specific blockade by a new class of drugs. Nature, 1985;31:316-326.
74. Boireau A, Bordier F, Durand G et al - The antidepressant metapramine is a low-affinity antagonist at N-methyl-D-aspartic acid receptors. Neuropharmacology, 1996;35:1703-1707.

75. Watanabe Y, Saito H, Abe K - Tricyclic antidepressants block NMDA receptor-mediated synaptic response and induction of long-term potentiation in rat hippocampal slices. Neuropharmacology, 1993;32:479-486.

76. Eisenach JC, Gebhart GF - Intrathecal amitriptyline acts as an $\mathrm{N}$-Metil-D-Aspartate receptor antagonist in the presence of inflammatory hyperalgesia in rats. Anesthesiology, 1995;83: 1046-1054

77. Malberg AB, Yaksh TL - Pharmacology of the spinal action of ketorolac, morphine, ST-91, U504488H and L-PIA on the formalin test and an isobolographic analysis of the NSAID interaction. Anesthesiology, 1993;79:270-281.

78. Choi Y, Raja SN, Moore LC et al - Neuropathic pain in rats is associated with altered nitric oxide synthase activity in neural tissue. J Neurol Sci, 1996;138:14-20.

79. Yaksh TL, Malmberg AB - Spinal nitric oxide synthesis inhibition blocks NMDA-induced thermal hyperalgesia and produces antinociception in the formalin test in rats. Pain, 1993;54: 291-300.

80. Omoigui S - The Pain Drugs Handbook. Ed. Mosby 1994;43, 173-262; 296; 302;431.

\section{RESUMEN}

Rocha APC, Lemonica L, Barros GAM - Uso de Medicaciones por Vía Subaracnóidea en el Tratamiento del Dolor Crónico

Justificativa y Objetivos - El dolor crónico es un desafío para la Medicina actual. Nuevos métodos y medicamentos han sido propuestos con el intento de controlar los síntomas álgicos. La vía de administración subaracnóidea se ha mostrado como una alternativa viable y segura, aun cuando, necesite continuamente ser objeto de estudio de muchos pesquisidores. El objetivo de este trabajo es hacer una revisión de los medicamentos disponibles en el arsenal terapéutico ya consagrados por el uso y los que se muestran prometedores en la actualidad para la práctica clínica diaria.

Contenido - En esta revisión son evaluados varios fármacos que presentan acción analgésica cuando utilizados por vía neuroejes. Opioides, anestésicos locales, agonistas $\alpha_{2}$-adrenérgicos, antagonistas de los aminoácidos excitantes e inhibitorios, acetilcolina, inhibidores de la acetilcolinesterasis bloqueadores de los canales de calcio, adenosina, serotonina, antidepresivos tricíclicos e inhibidores de la síntesis de prostaglandinas son analizados en lo que concierne a sus efectos farmacológicos, incluyendo los indeseables.

Conclusiones - Muchos avanzos fueron registrados en el control de los síntomas álgicos después de la utilización de las substancias citadas por vía raquidiana, donde ciertamente algunas serán aprovechadas y enriquecerán el arsenal terapéutico y otras relegadas temporaria o definitivamente. Entretanto, aun serán necesarios muchos estudios clínicos y experimentales para que estos conocimientos puedan ser incorporados y utilizados con seguridad por los profesionales que trabajan con el tratamiento del dolor crónico. 